\title{
Do megalitismo às gravuras rupestres: contribuições para a arqueologia da Região do Jalapão, Tocantins, Brasil
}

\author{
Jorge Eremites de Oliveira \\ Universidade Federal da Grande Dourados \\ Rodrigo Luiz Simas de Aguiar \\ Universidade Federal da Grande Dourados
}

O estado do Tocantins está circunscrito na região Norte do Brasil, conhecida mundialmente pela predominância de ecossistemas amazônicos com expressiva biodiversidade. No entanto, mais de $60 \%$ dos $277.620 \mathrm{~km}^{2}$ do território tocantinense estão inseridos em ecossistemas de cerrado, onde também há grande biodiversidade, cuja área está inclusa no chamado Brasil Central. Ali há um elevado potencial para a ocorrência de sítios arqueológicos associados a antigos grupos indígenas, situação esta constatada desde a década de 1970 para as porções do Médio Araguaia, Centro-Sul e Leste da unidade federativa.

Diante de um cenário desta natureza, a arqueologia tocantinense se mostra muito promissora, pois tem pela frente o desafio de estabelecer um contexto arqueológico mais aprofundado e uma cronologia mais apurada sobre os grupos humanos que ali se estabeleceram desde tempos pré-coloniais. 


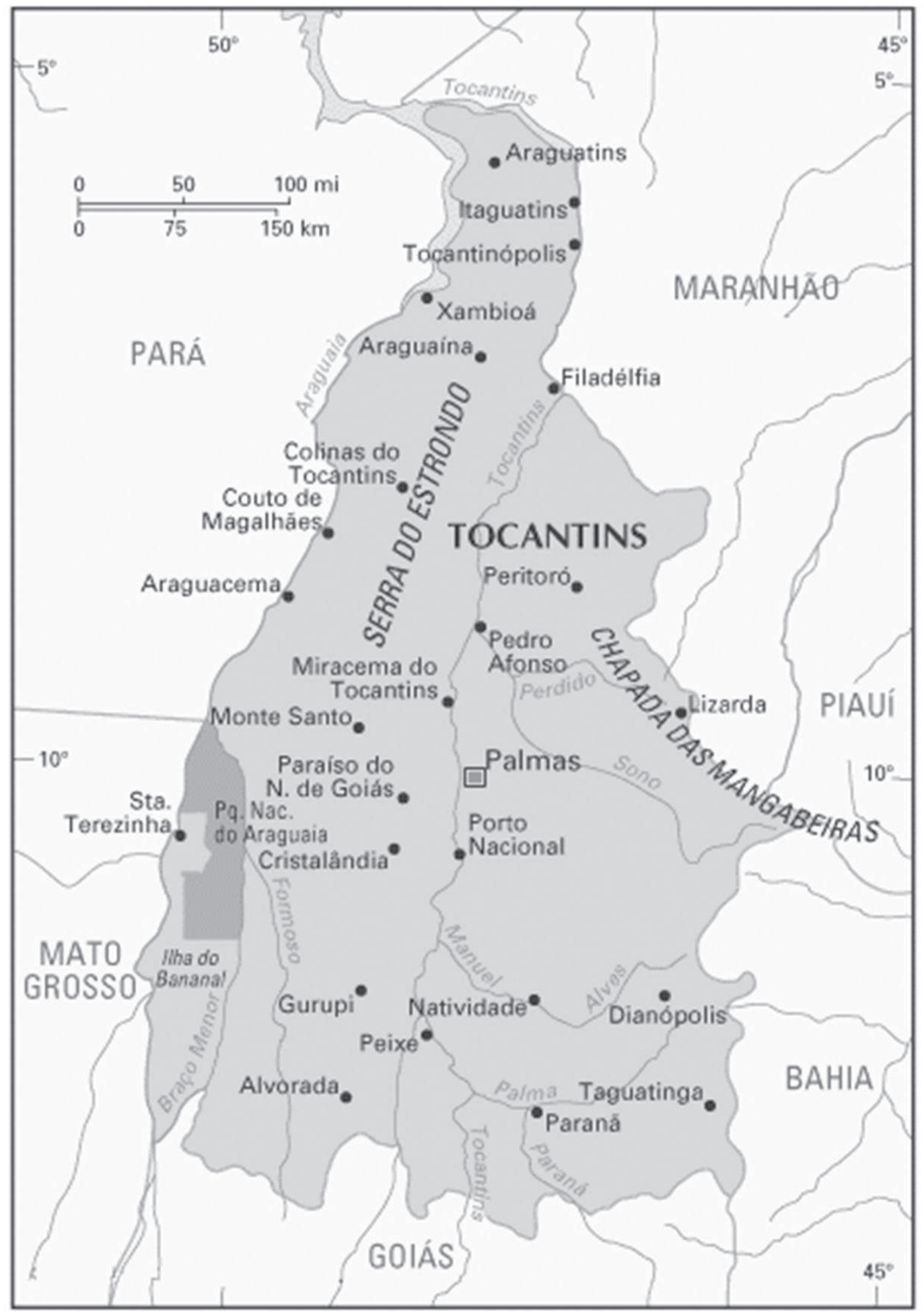

Figura 1: Localização do estado do Tocantins. Fonte: http://www.viagemdeferias. com/mapa/tocantins/ (acessado em 10/03/2010 [modificado])

Maracanan 
No caso da região do Jalapão, mais especificamente a área banhada pelo rio do Sono e seus afluentes, constatamos que ali a pesquisa arqueológica é praticamente inexistente ou desconhecida. Tal situação em hipótese alguma decorre da inércia dos arqueólogos que atuam no estado, pelo contrário; as equipes tocantinenses têm se empenhado sobremaneira para fazer frente a um elevado e crescente volume de trabalhos a elas apresentados. Tampouco é resultante do desinteresse dos arqueólogos, pois as paisagens de campos abertos e serras do Jalapão, somadas à potencialidade arqueológica regional, são ingredientes atrativos para os profissionais de arqueologia. A escassez de pesquisas talvez encontre certa fundamentação na inópia dos recursos financeiros destinados aos projetos arqueológicos, realidade científica constatada em muitos estados do Brasil, sobretudo no que se refere ao fomento público à pesquisa acadêmica stricto sensu. Por outro lado, o gradual aumento das pesquisas arqueológicas voltadas para o licenciamento ambiental de projetos desenvolvimentistas tem sido, com efeito, uma oportunidade para a produção e a socialização de novos conhecimentos sobre a região. Este é o caso dos dados apresentados neste artigo, os quais foram obtidos em 2009, durante a realização de pesquisas voltadas para a elaboração do diagnóstico arqueológico da área diretamente afetada por um empreendimento hidrelétrico proposto para ser instalado na área. As primeiras publicações foram destinadas ao grande público ${ }^{1}$, sendo esta a primeira versão mais elaborada e voltada a arqueólogos e profissionais de campos afins.

Não obstante, se existem dados registrados nos anais da arqueologia para o Tocantins, merecem créditos as pesquisas desenvolvidas pelas equipes do Instituto Anchietano de Pesquisas (IAP), da Pontifícia Universidade Católica de Goiás (PUC Goiás; antiga Universidade Católica de Goiás, UCG), da Universidade Federal de Goiás (UFG), do Instituto de Arqueologia Brasileira (IAB) e do Núcleo Tocantinense de Arqueologia (NUTA). Os trabalhos pioneiros desenvolvidos nessas instituições têm contribuído para a germinação de uma ciência arqueológica por todas as terras do Brasil Central.

Feita esta pequena digressão de caráter introdutório, cabe dizer que o presente artigo pretende colaborar com a formação de um pano de fundo arqueológico da região do Jalapão, instrumento este que será útil para subsidiar futuras pesquisas a serem empreendidas naquelas savanas tocantinenses. Entretanto, além do descerramento das ocorrências arqueológicas lá 
diagnosticadas, outro recorte temático deste artigo está centrado nos alinhamentos de pedras registrados durante as pesquisas que possibilitaram o levantamento dos dados empíricos que embasam o presente estudo.

\section{O contexto arqueológico do Tocantins}

Com base no que se tem conhecimento até o momento, os primeiros estudos arqueológicos sistemáticos no estado do Tocantins foram empreendidos em 1972 pela equipe do IAP, em parceria com a PUC Goiás e a UFG, quando o atual território tocantinense ainda fazia parte do estado de Goiás. Essas pesquisas integravam o Programa Arqueológico de Goiás, coordenado por Pedro Ignácio Schmitz, e parte dos dados obtidos durante as pesquisas consta publicada na obra Horticultores Pré-históricos do Estado de Goiás ${ }^{2}$. Em 1978, uma equipe formada por membros do IAP e da PUC Goiás estudou quatro sítios arqueológicos situados no município de Monte do Carmo, talvez uma das pesquisas arqueológicas mais próximas à região do Jalapão, ainda que distante mais de uma centena de quilômetros da sub-bacia hidrográfica do rio do Sono ${ }^{3}$.

A arqueologia do Tocantins também foi investigada pela equipe do IAB, sob a coordenação de Ondemar Ferreira Dias Jr. O potencial arqueológico do estado levou o IAB a estabelecer um convênio com a Universidade do Tocantins (UNITINS), onde atua o arqueólogo Marcos Zimmermann, sendo daí criado o NUTA. A união dos esforços desses dois arqueólogos culminou em diversos projetos de pesquisa arqueológica, bem como na condução de programas de salvamento e monitoramento de bens arqueológicos. Um panorama dos trabalhos foi publicado como capítulo em um livro denominado Estudos Contemporâneos de Arqueologia ${ }^{4}$.

Os mais antigos assentamentos humanos até agora registrados no Tocantins recuam para aproximadamente 10 mil anos atrás, período em que populações de caçadores-coletores desenvolviam uma indústria lítica lascada com raspadores plano-covexos e lâminas de dorso ${ }^{5}$. Cabe destacar que o clima daquele período inicial do Holoceno se diferenciava do atual, pois as alternâncias entre períodos mais secos e mais úmidos caracterizavam a região entre 10.500 e 7.250 AP (anos Antes do Presente) ${ }^{6}$. Trata-se de um momento em que "o frio e a secura do final da glaciação, acompanhados de uma vegetação mais rala, com

\section{Maracanan}


megafauna, cedem lugar à tropicalidade com vegetação mais desenvolvida e um novo quadro de fauna" 7 .

As populações de caçadores-coletores desse primeiro período assentavam-se pela vasta região de cerrado em acampamentos temporários e pouco freqüentes, explorando os recursos ambientais do entorno. Não havia ainda, ao menos em tese, ações de controle ou aumento dos produtos naturalmente disponíveis ${ }^{8}$, embora possa ter havido complexas formas de manejo agroflorestal ainda desconhecidas. Segundo os referidos autores, esses agrupamentos humanos ocupavam os campos de seixos e pequenos blocos-testemunhos circundantes. Contudo, sua presença em abrigos era muito rara, o que tem levado os pesquisadores a interpretar que esses caçador-coletores não seriam os autores da arte rupestre neles encontrada.

Esta primeira etapa de povoamento foi classificada por Pedro Ignácio Schmitz ${ }^{9}$ como a dos grupos portadores da 'tradição Itaparica' ${ }^{10}$. Entretanto, por suas características muito gerais, que podem ser encontradas em toda a região em questão, e face ao pouco conhecimento dos sistemas socioculturais pretéritos do Brasil Central, André Prous ${ }^{11}$ assevera que a 'tradição Itaparica' tem valor classificatório insuficiente. Tal situação evidencia a necessidade de ampliação das pesquisas arqueológicas na região e a importância em preservar os sítios arqueológicos ali existentes.

A expansão do bioma cerrado veio a ocorrer entre 6.500 e 4.000 AP, em uma variação climática holocênica ${ }^{12}$. O cerrado, com suas potencialidades faunísticas e florísticas, apresentava condições ecológicas extremamente propícias para abrigar populações humanas, favorecendo a sua reprodução física. Por este motivo "não é de se estranhar que os sítios arqueológicos, tanto de caçadores, como de horticultores, sejam abundantes"13. Uma descontinuidade cultural em relação ao período anterior foi verificada por Schmitz ${ }^{14}$ e constatada na indústria lítica e óssea, bem como na alimentação e nas pautas de sepultamento. Este novo momento de ocupação vai ser conhecido em algumas partes do Centro-Oeste como 'tradição Serranópolis'.

O aparecimento de grupos ceramistas em ambiente de cerrado, cuja tecnologia é comumente associada à presença da agricultura, ainda que incipiente, será marcado pela presença de uma indústria oleira de quase 4 mil anos, conhecida por 'tradição Una'15. André Prous caracteriza esta tradição pela produção de recipientes de pequena dimensão, raramente ultrapassando 
os $22 \mathrm{~cm}$ de diâmetro, e pela ausência de decoração plástica no vasilhame. É importante destacar que o autor classificou a cerâmica descoberta por Schmitz em Monte do Carmo, no Tocantins, e datada de 410 a.C. ${ }^{16}$ (Barbosa et al., 1982), como correspondente à 'tradição Una'. Entretanto, existem muitos problemas classificatórios diante da carência de dados referentes aos povos pré-coloniais naquele estado. A própria equipe do IAP inicialmente apontou a possibilidade de os ceramistas de Monte do Carmo serem os portadores da tecnologia ceramista conhecida como 'tradição Aratu'. Por este motivo chegou a percebê-los como portadores da 'fase Pindorama', uma subdivisão dessa tradição tecnológica ceramista:

A semelhança com a tradição Aratu/Sapucaí está no antiplástico mineral (quartzo, feldspato, mica, grafite), nas formas simples globulares ou piriformes, na falta de decoração, com exceção de um eventual banho vermelho. O grafite é um bom indicador para a tradição Aratu (Barbosa et al., 1982: 72). ${ }^{17}$

Não obstante à explicação apresentada, em publicação posterior esta cerâmica foi descrita pela mesma equipe como 'Tradição não definida da Fase Pindorama'18. Sobre as ocupações cerâmicas do Tocantins, Ondemar Dias Jr. et al. ${ }^{19}$ afirmam que as evidências são, em sua maioria, vinculadas a povos da tradição 'Aratu-Sapucaí', reforçando a hipótese da equipe do IAP. Todavia, sobre este problema classificatório, recentemente Walter Fagundes Morales $^{20}$ acrescentou que a associação da 'fase Pindorama' do sítio Monte do Carmo com a 'tradição Aratu' seria um equívoco. Em sua opinião, essas ocorrências arqueológicas pertenceriam, na verdade, à 'tradição Una', cuja tese vai ao encontro com o que foi proposto anteriormente por André Prous. Tal posição contrária não implica no fato de que qualquer destes autores tenha pecado por imprecisão em suas pesquisas. Evidencia-se, isto sim, o atual estado da arte da arqueologia regional e a necessidade de se construir um quadro ocupacional mais preciso para o estado do Tocantins, algo que só pode ser atingido por meio de mais pesquisas arqueológicas.

Ainda sobre os ceramistas portadores da 'tradição Una', estes teriam se estabelecido em ambientes de relevo acidentado em meio ao cerrado. Por vezes ocuparam as mesmas grutas anteriormente utilizadas pelos grupos aceramistas

\section{Maracanan}


caçadores-coletores, ainda que também ocorram sítios a céu aberto vinculados a esta mesma tradição ceramista ${ }^{21}$. Acredita-se que os grupos portadores da 'tradição Una' mantiveram uma agricultura incipiente iniciada por caçadores e coletores tardios, conforme defendido por Irmhild Wüst ${ }^{22}$.

Também sobre o surgimento de grupos ceramistas no estado do Tocantins, Elisângela Regina de Oliveira ${ }^{23}$ explicou que os primeiros aldeamentos ceramistas, como pertencentes às tradições 'Uru' e 'Aratu', decorreram de um processo de interação entre essas tradições tecnológicas ceramistas. Um processo desse nível teria sido tão intenso a ponto de criar células de fusão entre ambas, resultando daí um amálgama tecnológico que sugere a emergência de outras etnicidades na região, fenômeno este que teria aumentado e diversificado ainda mais o mosaico sociocultural ali existente.

A 'tradição Uru' está presente na região Centro-Oeste desde, ao menos, o século VIII da Era Cristã. Para o alto Tocantins, os registros arqueológicos apontam para uma ocupação mais recente, do décimo segundo século da nossa era. Existe a hipótese de que os grupos portadores dessa tradição tenham chegado até os tempos da conquista, o que sustentaria a idéia de que alguns sítios mais recentes estariam associados aos índios Karajá. A cerâmica da 'tradição Uru' possui características que lhes são peculiares, com antiplástico mineral e vegetal (cariapé), vasilhames em sua maioria não decorados (apesar de alguns exemplares contarem com decoração pintada ou plástica) e formas que vão de pratos e panelas a tigelas e jarros ${ }^{25}$. O material lítico também é abundante, com presença de machados polidos.

Por fim, uma quarta tradição cerâmica aparece nos registros arqueológicos da região Centro Oeste, a 'tradição Tupiguarani'. Apesar dos ceramistas portadores dessa tradição tecnológica ceramista serem tidos como originários da região amazônica, sítios arqueológicos a ela associados ocorrem em vários pontos do Brasil, do litoral às terras interioranas. São estes os produtores dos grandes vasos cerâmicos, conhecidos na literatura por 'igaçabas' e 'japepó', cujas decorações vão da pintada à plástica. Quanto à produção ceramista, foi constatado que em muitos pontos do Brasil Central há maior predomínio da decoração pintada ${ }^{26}$.

Apesar de existir material cerâmico proveniente de sítios arqueológicos tocantinenses em coleções museológicas e laboratórios, o labor classificatório e comparativo ainda está no começo. Também há muito material por 
processar, o que impede uma precisa associação das ocorrências cerâmicas a uma tradição em particular. Na sub-bacia hidrográfica do rio do Sono, em especial, a ausência de estudos arqueológicos dificulta ainda mais a contextualização do processo de ocupação humana no Jalapão.

Com o passar do tempo, o adensamento dos grupos indígenas pré-coloniais resultou na sociodiversidade ameríndia constatada para o Tocantins a partir do século XVIII, conforme indicado por Odair Giraldin ${ }^{27}$ : Karajá, Krahô, Nhyrkwãnje, Apinajé, Akroá, Xakriabá, Xavante, Xerente e AváCanoeiro. No entanto, listagens desse tipo devem ser vistas com cautela porque a diversidade étnica do atual território tocantinense deveria ser bem maior em tempos coloniais do que a existente nos dias de hoje.

Quanto à organização social, "as populações indígenas que habitavam o território do Tocantins na época da chegada dos europeus eram sociedades tribais típicas, organizadas em linhagem de parentesco" e "[...] ocupavam vastos territórios comunais (áreas vitais) de onde retiravam a subsistência" 28 . A agricultura de coivara era o método de cultivo empregado por essas sociedades tribais, no qual entre os principais produtos colhidos destacam-se o milho, a abóbora e a batata-doce ${ }^{29}$.

A bacia hidrográfica do Tocantins é um manancial de recursos ictiofaunísticos, cuja exploração esteve ligada à trajetória econômica das populações tradicionais. A habilidade pesqueira foi desenvolvida com base em técnicas de captura amplamente conhecidas na etno-história, dentre as quais estão o uso do arco e flecha, a elaboração de armadilhas e o emprego de redes. A arqueologia comprova que a pesca por meio de anzóis feitos em ossos integrava a atividade pesqueira nos cerrados do Brasil Central desde os tempos pré-coloniais $^{30}$. O uso de extratos vegetais - como o 'timbó' - para envenenamento dos cardumes também figura na tecnologia pesqueira de algumas tribos indígenas do Tocantins ${ }^{31}$.

O contato entre os conquistadores europeus e euroamericanos e as sociedades indígenas foi intenso e belicoso em terras tocantinenses. As primeiras narrativas aparecem em um contexto marcado por dois momentos econômicos: o minerador e o agro-pastoril. O momento de mineração atraiu muitos colonos no afã de garimpar as riquezas presentes no antigo substrato goiano, incluindo o atual território tocantinense. Os antigos garimpos desta etapa da história regional são vestígios arqueológicos ainda pouco estudados e em

\section{Maracanan}


quase nada mapeados. O etno-historiador Cleube Alves da Silva ${ }^{32}$ destaca que os antigos mineradores viviam em constantes confrontos armados com as etnias indígenas locais. Com o esgotamento da mineração, ocorreu um temporário esvaziamento do contingente não indígena.

Não demorou até que um novo momento econômico se desenrolasse pelas terras do Brasil Central. O estabelecimento das grandes fazendas, como parte das estratégias das frentes de expansão da sociedade nacional e seus antecessores coloniais, implicava a expropriação do território tradicional indígena, o que também gerou inúmeros confrontos armados. Entre os grupos que esboçaram resistência frente à expansão econômica colonial, estavam os Xakriabá. Eles formaram "um grupo que resistiu à conquista, aliou-se a outros grupos indígenas para a guerra contra o luso-brasileiro e ao conquistador para as lutas intestinas com grupos rivais" ${ }^{33}$. Esse modus operandi, decorrente de uma adaptação cultural face aos diferentes momentos dos contatos interétnicos em Goiás, foi o que garantiu a sobrevivência do grupo.

Mediante as pressões das frentes de expansão, os povos indígenas iniciaram um processo de movimentação territorial, envolvendo territorializações, desterritorializações e reterritorializações. Diante da diminuição dos espaços disponíveis e em detrimento do drástico saldo dos combates, pouco a pouco as diferentes tribos se viram enquadradas em um novo processo de territorialização, o aldeamento em áreas a eles reservadas pelo Estado Nacional. O desfiar deste processo acarretou o quadro de aldeamentos que hoje se apresenta para o Tocantins.

\section{Ocorrências arqueológicas na região do Jalapão}

A área situada na região leste do estado do Tocantins, que intercala estepes arenosas com campos verdejantes, é conhecida pelo nome de Jalapão. É precisamente nesta área, ainda praticamente desconhecida pela arqueologia, que foi empreendida a pesquisa que subsidiou este artigo. Para o viajante desavisado, alguns locais da região podem ser confundidos com a representação sobre a desértica caatinga. Com efeito, existe uma parte deste bioma que é conhecida como Deserto do Jalapão. Neste lugar a vegetação é mais esparsa e o mandacaru - cacto de porte arbóreo - aparece com frequência.

Janeiro | Dezembro 2011 
Mas, diferentemente de outras zonas desérticas onde a vida é quase impossível, o Jalapão é berçário de muitas espécies importantes dos cerrados do Brasil Central. Tal condição só é possível porque estas savanas são fartas em água, seja pelos seus muitos rios e córregos, seja pelo vasto lençol freático que se espalha por toda a região.

O diagnóstico do potencial arqueológico do Jalapão foi elaborado por meio de uma parceria entre o Laboratório de Arqueologia, Etnologia e Etnohistória (ETNOLAB) e a Scientia Consultoria Científica. ${ }^{34}$ Os doze dias de trabalhos de campo revelaram dezoito sítios arqueológicos, demonstrando que as estepes do Jalapão foram ocupadas por diferentes povos em um passado distante.

A área avaliada está circunscrita na sub-bacia do rio do Sono, composta pelo rio homônimo e seus tributários. Evidentemente, face à dimensão da área, foi necessário optar por vistoriar regiões cujas características ecológicas se mostravam propícias para a ocorrência de sítios arqueológicos. Significa dizer que o método preditivo empregado para a identificação de sítios arqueológicos foi o mesmo usado por muitas equipes de arqueólogos, nas quais prospecções não intrusivas e oportunísticas foram conduzidas em áreas potencialmente favoráveis para a ocorrência de sítios arqueológicos: margens de rios, abrigos sob rocha e outros locais propícios para acomodar assentamentos humanos, sendo que para tanto a interpretação do ambiente tem papel destacado ${ }^{35}$.

As primeiras populações humanas do Jalapão viviam de uma economia baseada na caça, pesca e coleta, sustentável graças ao copioso recurso alimentar do cerrado e ao emprego de conhecimentos práticos desenvolvidos ao longo de gerações e de muitas trocas culturais. Estas atividades de subsistência eram instrumentalizadas por uma indústria lítica lascada, provavelmente acompanhada de utensílios em madeira e ossos, mas que se deterioraram com a ação dos milênios. Por isso dificilmente são encontrados pelos arqueólogos. Estes instrumentos em pedra lascada muito se assemelham àqueles descritos para a 'tradição Itaparica', constituídos basicamente de núcleos, lascas e lâminas.

Curiosamente, as ocorrências arqueológicas encontradas no Jalapão estão localizadas preferencialmente nos rios menores e córregos, tributários do rio do Sono. A opção pelos tributários sugere um padrão de assentamento que

\section{Maracanan}


prioriza os fluxos de água de menor bojo. Nestes rios menores e córregos, percebem-se elevada ocorrência de pescado, visíveis pela pouca profundidade e pela transparência da água. Para a pesca com 'timbó', armadilhas ou arco e flecha esses córregos são muito mais propícios. Outrossim, são boas fontes de água potável, elementos que justificariam o padrão de assentamento observado. Constatou-se a existência de sítios arqueológicos às margens dos rios Monte Santo e Vermelho, bem como dos córregos Espingarda, Caracol, Rapadura, Olimpo, Formosa e Brejão. Esses rios e córregos ocupam áreas dentro de quatro municípios tocantinenses: Novo Acordo, Lizarda, Rio Sono e São Félix.

Duas questões fundamentais surgiram a partir da distribuição dos sítios: a primeira é se a preferência pelos córregos e rios menores se dava de acordo com o que se conhece para as tradições tecnológicas registradas na região, ou seja, se este padrão estaria limitado a determinadas ocupações; a segunda, e intimamente ligada à primeira, é se quando dos primeiros assentamentos humanos no Tocantins, há cerca de 12.000 anos, o curso destes tributários era o mesmo de hoje, haja vista que se trataria de um paleoclima, anterior ao Ótimo Climático. Caso esses córregos seguissem um traçado distinto, as ocupações mais antigas estariam situadas em outros locais ainda não vistoriados. De fato, registrou-se um único sítio arqueológico às margens do rio do Sono, cujas características o aproximariam da chamada 'tradição Itaparica'. Entretanto, é prudente ressaltar que se tratou de uma avaliação que priorizou determinadas áreas, porquanto seria impossível percorrer em tempo hábil todas as margens dos rios e córregos que compõem a sub-bacia do rio do Sono. Ou seja, um levantamento sistemático pode revelar muitos outros sítios arqueológicos, o que não seria de se estranhar em uma área tão rica em termos de biodiversidade e sociodiversidade.

Ocupações cerâmicas também foram registradas na região do Jalapão. Às margens do rio Monte Santo há dois antigos assentamentos de grandes dimensões, sendo que ambos ocorrem em áreas mecanizadas para cultivo. Infelizmente, a cerâmica apresentava-se muito fragmentada devido ao preparo do solo pelo trator. Esses sítios, do tipo litocerâmico, apresentam características que muito os aproximam das descrições referentes à 'tradição Aratu'. As cerâmicas foram avaliadas apenas in loco, pois nenhum material arqueológico foi coletado. Como o material apresentava-se muito fragmentado e não 
foram coletadas amostras para serem analisadas em laboratório, uma precisa classificação dessa cerâmica dependerá de estudos futuros que envolvam coletas, prospecções intrusivas e trabalhos de laboratório. Também no município de Rio Sono, porém distante do rio homônimo, a equipe do NUTA registrou cinco sítios arqueológicos, todos litocerâmicos.

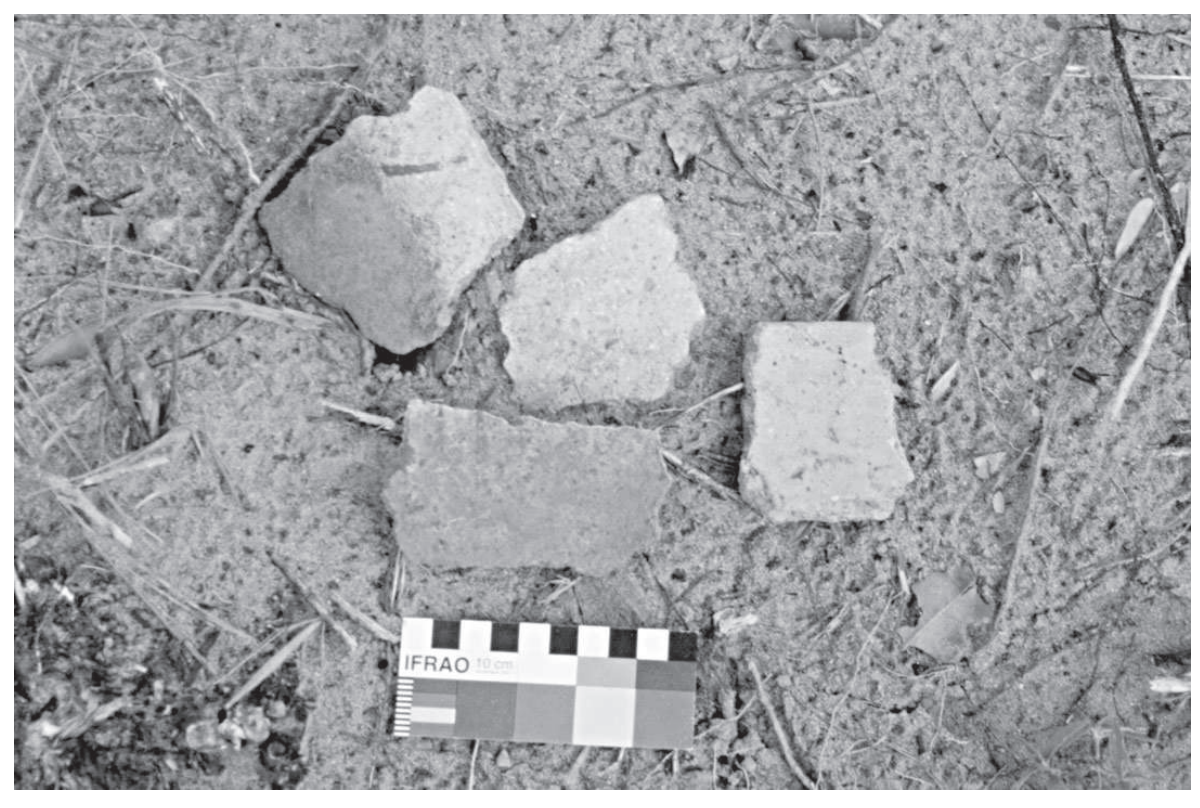

Figura 2: Fragmentos de cerâmica em sítio litocerâmico localizado às margens do Rio Monte Santo, município de Rio Sono.

A população local tem muita dificuldade de perceber a existência de sítios arqueológicos. Mesmo em áreas com farta ocorrência de cerâmica, as pessoas envolvidas no labor campesino afirmam desconhecer este tipo de evidência. Por outro lado, é recorrente na fala popular os fenômenos dos 'amontoados de pedras' e dos 'alinhamentos', que são associados a índios de um passado distante.

Os amontoados, que são montículos artificiais de seixos de aproximadamente $2 \mathrm{~m}$ de diâmetro por poucas dezenas de centímetros de altura, assemelham-se a sepulturas e ocorrem com relativa frequência. Em uma única propriedade, situada às margens do rio Vermelho, foram registrados oito montículos de seixos. Aparentemente, a distribuição destes montículos não apresenta qualquer relação com os pontos cardeais. Ao acessar a literatura arqueológica, encontra-se o registro de um sepultamento recoberto

\section{Maracanan}


por pedras na área de Monte do Carmo, conforme publicação da equipe do $\mathrm{IAP}^{36}$, o que aumenta as expectativas quanto à possibilidade destes montículos do rio Vermelho serem sepulturas do período pré-colonial. Se o forem, isto sugere a existência de diferenciação social entre indivíduos que foram sepultados dessa maneira e os que foram de outra.

Os mais intrigantes dos vestígios arqueológicos encontrados na região do Jalapão são os alinhamentos de pedras, modalidade de sítio arqueológico aparentemente inédito para o estado do Tocantins. Os três sítios registrados possuem características muito particulares, que vão do enfileiramento de pequenos seixos ao alinhamento de grandes blocos.

O primeiro sítio dessa modalidade é um alinhamento composto de grandes blocos ligados pelo enfileiramento de pequenos seixos. O local de ocorrência é um platô, no alto de um serro, cercado por baixios e pelo rio Monte Santo, o que confere uma visão panorâmica do entorno. Este alinhamento, situado no município de Rio Sono, foi parcialmente destruído pelo proprietário da fazenda, quem, desconhecendo a origem da estrutura, movimentou as pedras com um trator a fim de liberar a passagem para o gado. Entretanto, as pedras maiores, parcialmente enterradas, não puderam ser movidas pela máquina. Tomaram-se os pontos de georreferenciamento a partir das pedras não movidas a fim de reconstituir o alinhamento. Trata-se de um pequeno 'muro', de 83 metros de comprimento, alinhado no sentido leste-oeste. As características apresentadas levaram os pesquisadores a pensarem que tais alinhamentos estariam associados a uma espécie de culto solar ou que fizesse parte de um sistema mais complexo de comunicação com os astros, mesmo porque os alinhamentos parecem ordenados em virtude de um determinado solstício.

O segundo alinhamento, localizado no município de São Félix, está totalmente preservado e parece o ponto de partida ideal para um estudo arqueoastronômico. O alinhamento é formado por 18 blocos de pedra enterrados, alguns com mais de $50 \mathrm{~cm}$ expostos a partir do solo, seguindo um preciso ordenamento leste-oeste. Trata-se de um sítio arqueológico distante poucos metros do córrego Caracol, o qual em muito se aproxima de uma tradição megalítica.

Janeiro | Dezembro 2011 


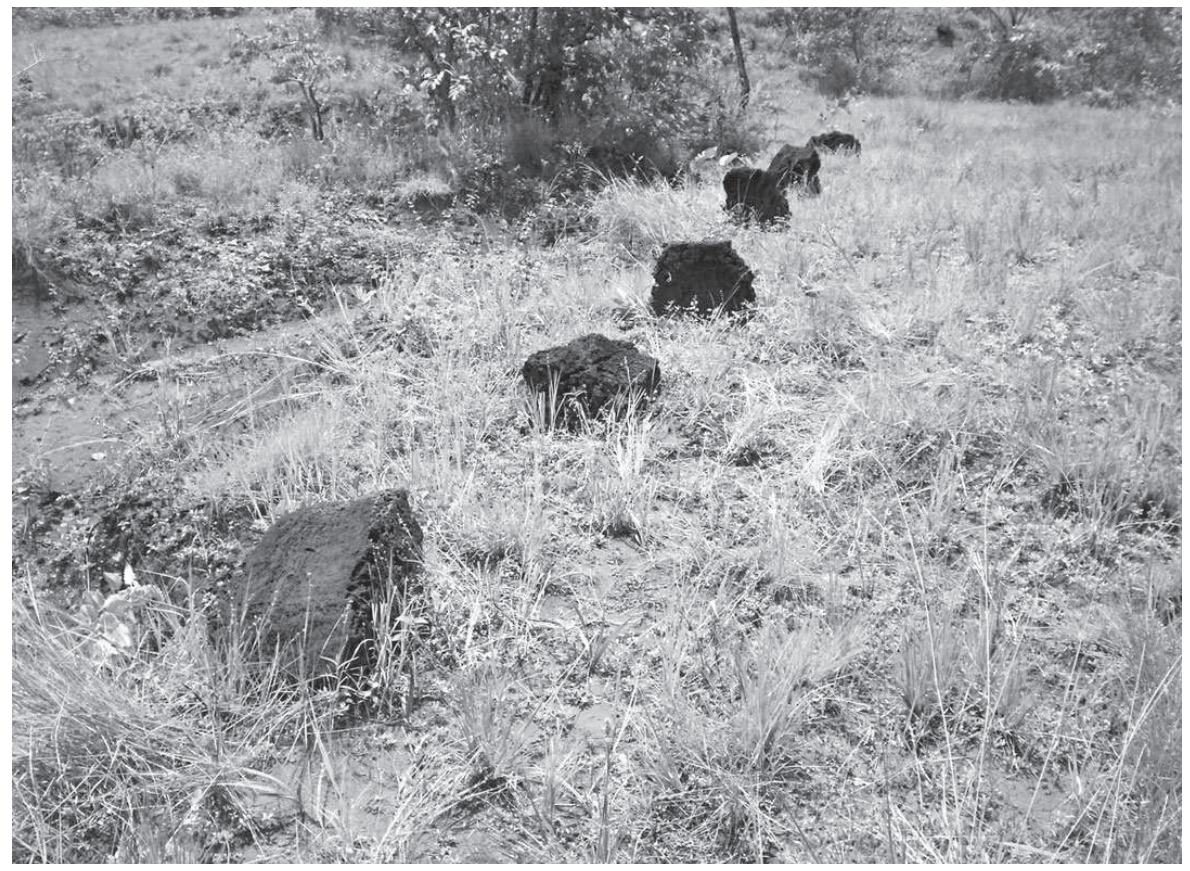

Figura 3: Alinhamento de pedras do município de São Félix.

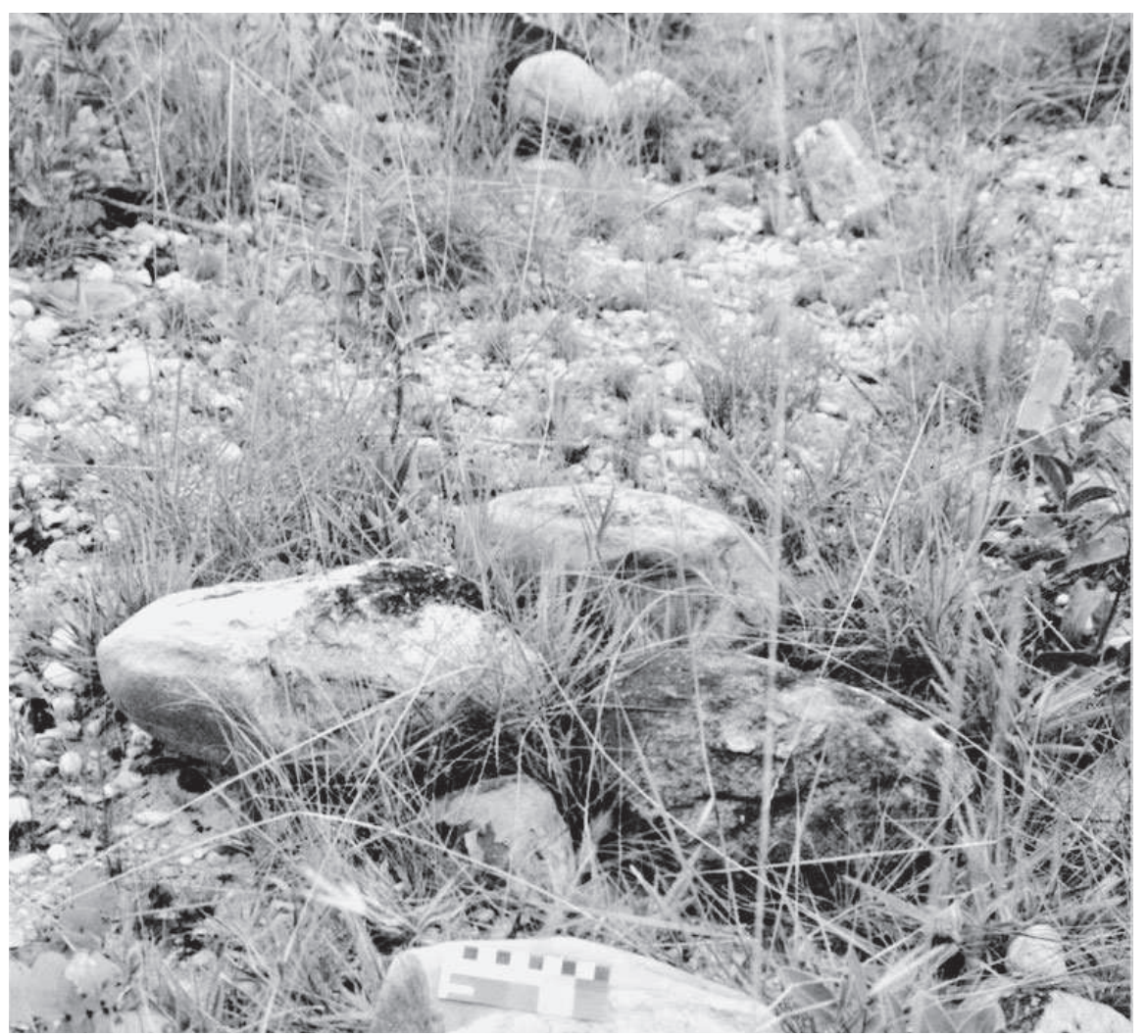

Figura 4: Alinhamento próximo ao rio Monte Santo, município de Rio Sono, parcialmente destruído.

\section{Maracanan}




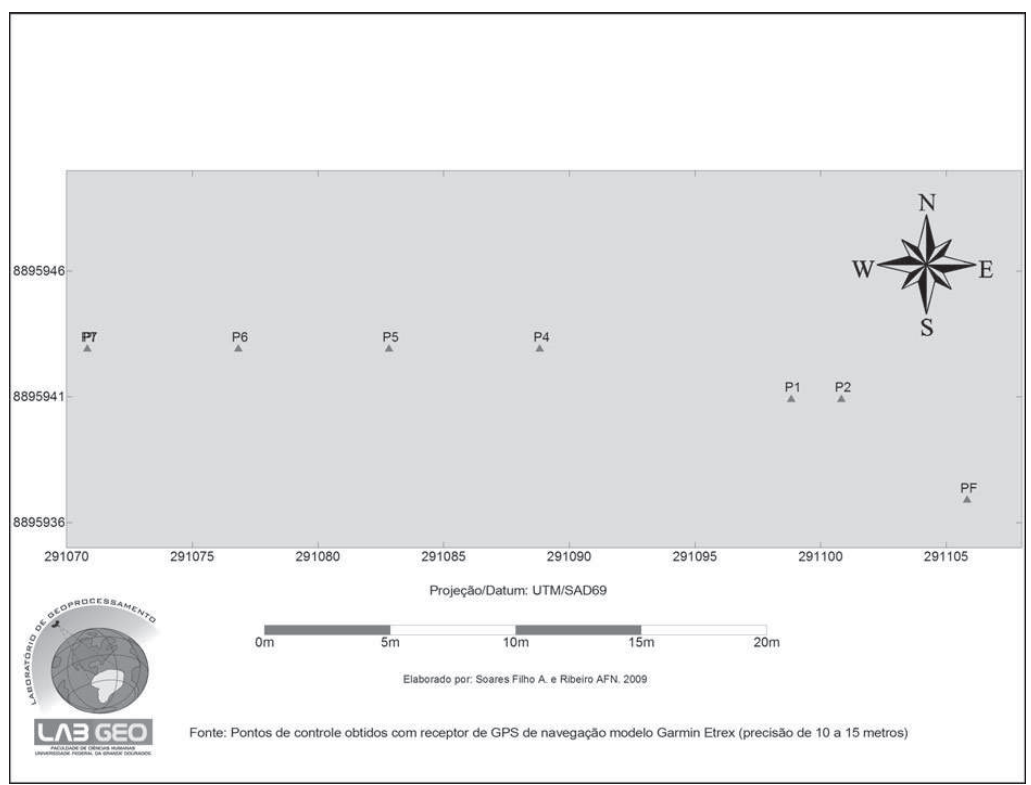

Figura 5: Reconstituição gráfica do alinhamento de Rio Sono e sua disposição em relação aos pontos cardeais.

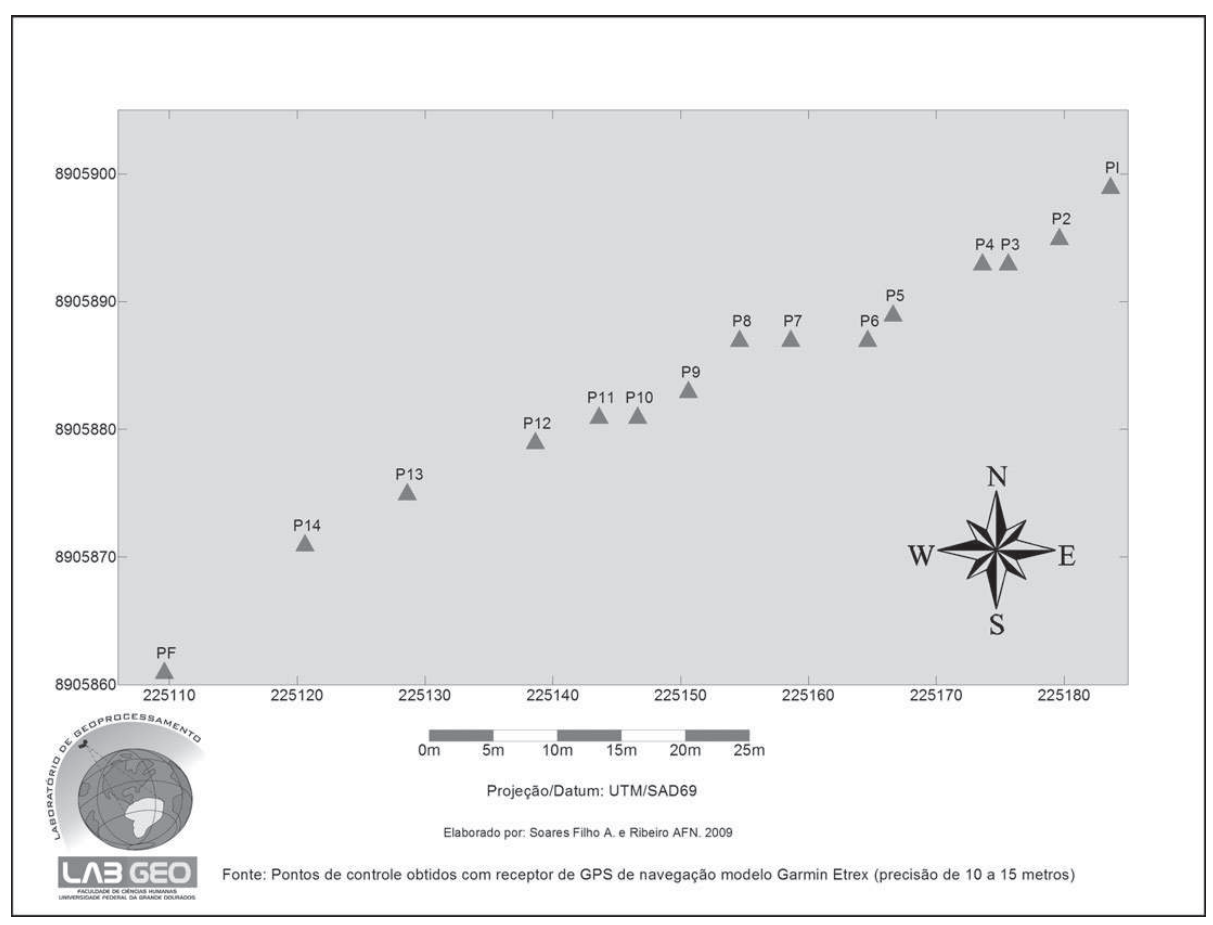

Figura 6: Reconstituição gráfica do alinhamento de São Félix e sua relação com os pontos cardeais.

Janeiro | Dezembro 2011 
Em Lizarda registrou-se um sítio arqueológico que segue um intrigante padrão de arranjo de pedras. Os autores dessa estrutura conceberam uma forma esquematizada em uma laje de arenito, feito por meio do enfileiramento de pequenos seixos de não mais que $30 \mathrm{~cm}$ de diâmetro. A forma do alinhamento lembra o desenho de uma casa, dividida em quatro cômodos, e cujas linhas externas perfazem um perímetro de 4,8 x 4,3 m. Quando indagados sobre estas ocorrências, os habitantes locais asseveram que seus ascendentes, que ali viveram há muitas décadas, já desconheciam os autores desses arranjos de pedras e creditavam o feito a índios do passado.

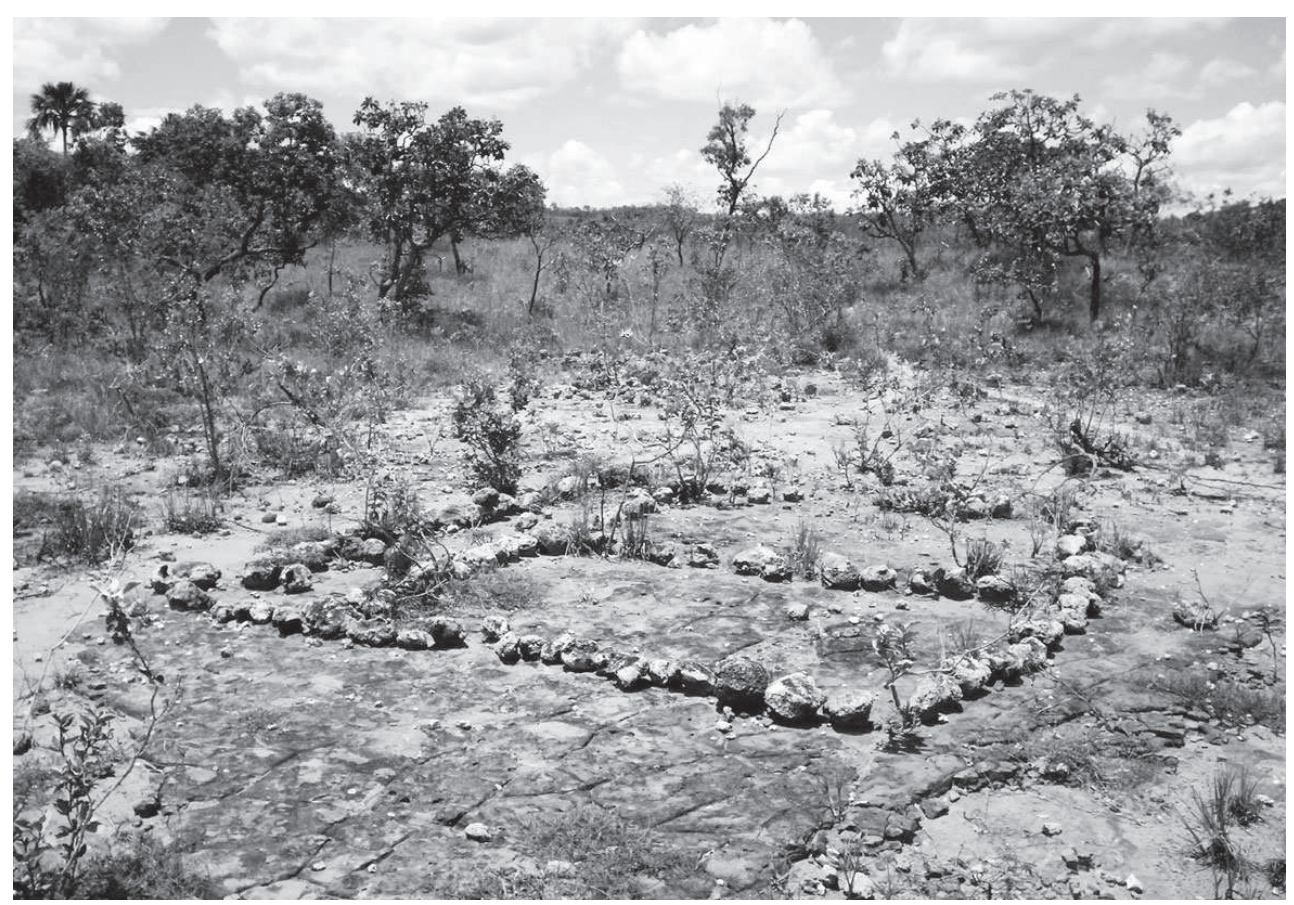

Figura 7: Arranjo de pedras do município de Lizarda.

Os alinhamentos de pedras dos córregos Espingarda e Caracol estão em locais onde fontes de água sustentam bolsões de vegetação que se sobressaem em uma paisagem quase desértica, formada por esparsas formações florísticas e serras avermelhadas de arenito, acompanhadas de algumas veredas e muitos mandacarus. Essas serras, onde ocorrem abrigos em abundância, aparentemente não apresentam vestígios de habitação ou de arte rupestre. Os sítios de arte rupestre vão ocorrer quase uma centena de quilômetros antes, em locais com vegetação mais intensa, sendo que em alguns pontos a paisagem quase se assemelha ao bioma mata atlântica.

\section{Maracanan}


O primeiro destes sítios de arte rupestre está em um local conhecido como Morro do Homem. Trata-se de uma grande formação em arenito, com diversos abrigos em sua circunferência. Cada um destes abrigos possui gravações rupestres, sendo que o maior dos abrigos guarda, por sua vez, a maior concentração de petroglifos. $O$ chão deste abrigo maior apresenta-se muito perturbado, pois os diferentes usos contemporâneos do local, como espaço para festas ou celebração de cultos, ocasionaram a remoção de sedimentos e a colocação de uma estrutura de pedra para sustentação do chão.

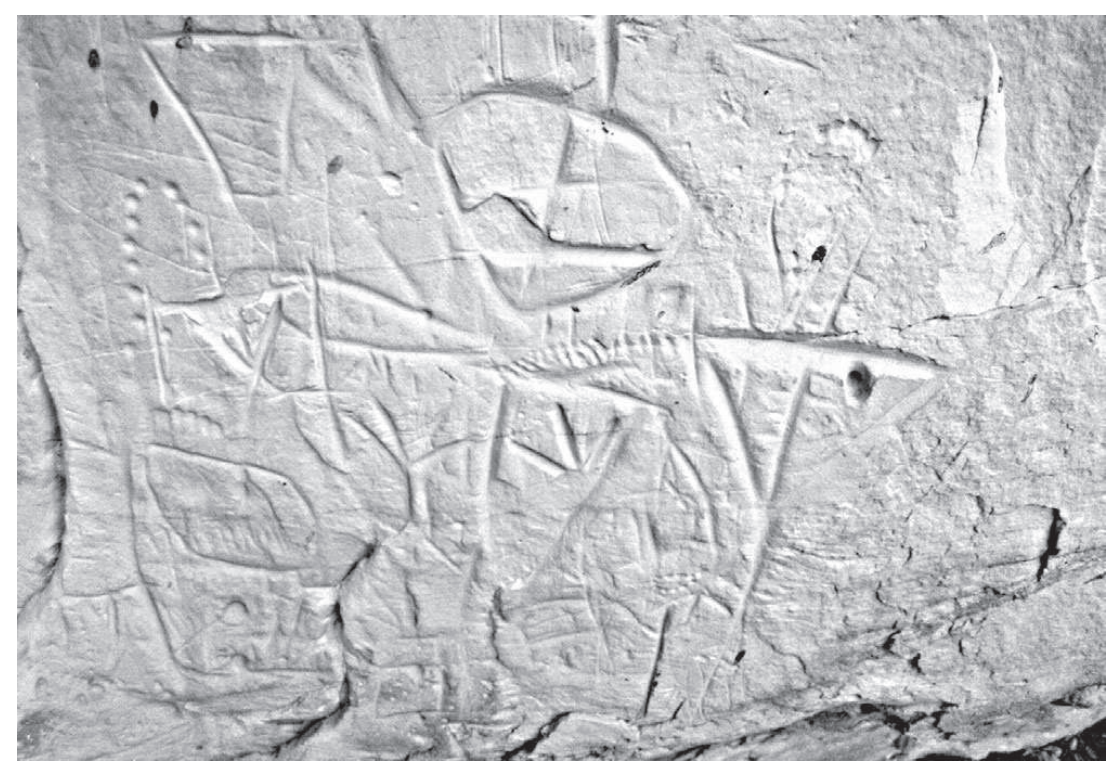

Figura 8: Petroglifos do Morro do Homem, município de Novo Acordo.

Os grafismos rupestres do Morro do Homem foram elaborados a partir de linhas polidas sobre as paredes de arenito, em formas geométricas variadas, com maior ocorrência dos tridáctilos, triângulos, vulvas e pegadas de animais, características descritas por André Prous ${ }^{37}$ como pertencentes à conhecida 'tradição Geométrica Meridional', a qual foi compartilhada por vários grupos étnicos. Os motivos são análogos aos encontrados pela equipe do IAP em Monte do Carmo ${ }^{38}$.

O segundo sítio de arte rupestre está localizado no município de Rio Sono, cujo acesso se dá a partir da localidade de Novo Horizonte, desde onde se segue um roteiro de aproximadamente $30 \mathrm{~km}$. Trata-se de uma caverna em local distante, onde a interferência contemporânea é muito 
reduzida. Na entrada da lapa aparecem algumas pinturas, já em estado de vestígio. O valor arqueológico desta caverna é grande, haja vista que uma escavação naquele local possibilitaria um estudo em contexto muito pouco perturbado. O motivo mais aparente é uma representação solar, situado à esquerda da entrada. À direita aparecem outros motivos, como uma cruz e linhas cruzadas.

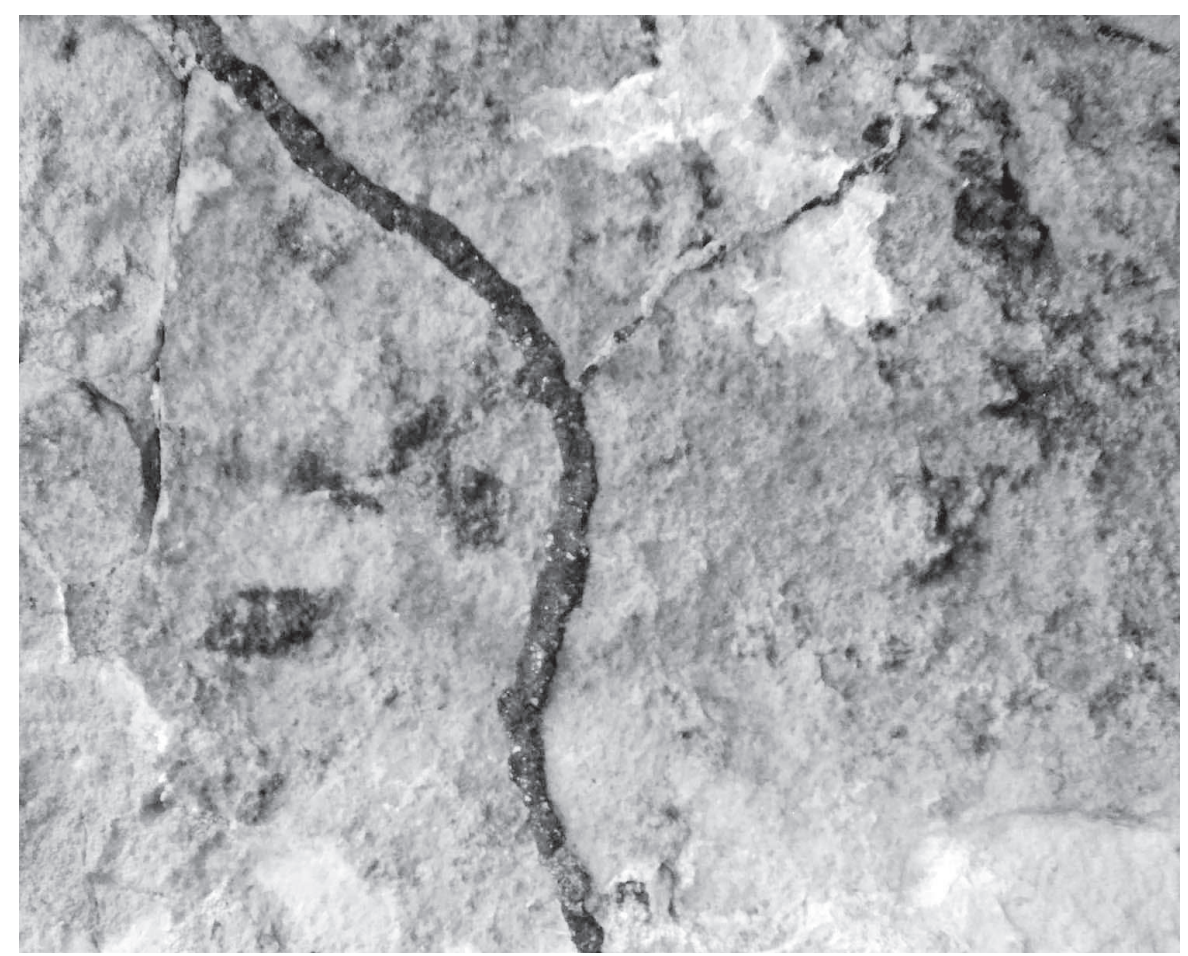

Figura 9: Pintura rupestre da Caverna do Sol, município de Rio Sono.

\section{Maracanan}




\section{Quadro 1 - Lista dos sítios arqueológicos registrados na região do Jalapão com as respectivas coordenadas em UTM.}

\begin{tabular}{|c|c|c|c|}
\hline UTM & LOCALIDADE & CIDADE & OCORRÊNCIA \\
\hline $\begin{array}{l}0210332 \mathrm{E} \\
8895426 \mathrm{~N}\end{array}$ & $\begin{array}{l}\text { Córrego Formosa, Fazenda } \\
\text { Famosa }\end{array}$ & Novo Acordo & Lítico \\
\hline $\begin{array}{l}0212739 \mathrm{E} \\
8894306 \mathrm{~N}\end{array}$ & Córrego Lajeado & Novo Acordo & Antigo garimpo \\
\hline $\begin{array}{l}0251813 \mathrm{E} \\
8879370 \mathrm{~N}\end{array}$ & $\begin{array}{l}\text { Ponto da Rodovia } \\
\text { Estadual } 030\end{array}$ & Novo Acordo & $\begin{array}{l}\text { Montículo } \\
\text { de pedras }\end{array}$ \\
\hline $\begin{array}{l}0245071 \mathrm{E} \\
8874766 \mathrm{~N}\end{array}$ & $\begin{array}{l}\text { Fazenda Pai e Filho } \\
\text { (rio Vermelho) }\end{array}$ & Novo Acordo & $\begin{array}{l}\text { Montículos } \\
\text { de pedras }\end{array}$ \\
\hline $\begin{array}{l}0274836 \mathrm{E} \\
8882952 \mathrm{~N}\end{array}$ & Margem do Rio Sono & Novo Acordo & Lítico \\
\hline $\begin{array}{l}0228191 \mathrm{E} \\
8900192 \mathrm{~N}\end{array}$ & $\begin{array}{l}\text { Fazenda Mato Grosso } \\
\text { (próximo ao córrego } \\
\text { Rapadura) }\end{array}$ & Rio Sono & $\begin{array}{l}\text { Chão de } \\
\text { Habitação }\end{array}$ \\
\hline $\begin{array}{l}0228509 \mathrm{E} \\
8894636 \mathrm{~N}\end{array}$ & $\begin{array}{l}\text { Caminhamento nas } \\
\text { dependências da Fazenda } \\
\text { Boa Nova }\end{array}$ & Rio Sono & Lítico \\
\hline $\begin{array}{l}0217619 \mathrm{E} \\
8895714 \mathrm{~N}\end{array}$ & $\begin{array}{l}\text { Fazenda Brejo das Canoas } \\
\text { (margem do rio Monte } \\
\text { Santo, ponto 1) }\end{array}$ & Rio Sono & Litocerâmico \\
\hline $\begin{array}{l}0216435 \mathrm{E} \\
8896022 \mathrm{~N}\end{array}$ & $\begin{array}{l}\text { Fazenda Brejo das Canoas } \\
\text { (margem do rio Monte } \\
\text { Santo, ponto 2) }\end{array}$ & Rio Sono & Litocerâmico \\
\hline $\begin{array}{l}0225229 \mathrm{E} \\
8905942 \mathrm{~N}\end{array}$ & $\begin{array}{l}\text { Serra do Buritizal } \\
\text { (Fazenda Alô Brasil) }\end{array}$ & Rio Sono & $\begin{array}{l}\text { Alinhamento } \\
\text { de pedras }\end{array}$ \\
\hline $\begin{array}{l}0263602 \mathrm{E} \\
8899072 \mathrm{~N}\end{array}$ & Rio Espingarda & Lizarda & $\begin{array}{l}\text { Alinhamento } \\
\text { de pedras }\end{array}$ \\
\hline $\begin{array}{l}0291130 \mathrm{E} \\
8895984 \mathrm{~N}\end{array}$ & Rio Caracol & São Félix & $\begin{array}{l}\text { Alinhamento } \\
\text { de pedras }\end{array}$ \\
\hline $\begin{array}{l}0287707 \mathrm{E} \\
8873806 \mathrm{~N}\end{array}$ & $\begin{array}{l}\text { Confluência dos rios Sono } \\
\text { e Novo }\end{array}$ & São Félix & Lítico \\
\hline
\end{tabular}

Janeiro | Dezembro 2011 


\begin{tabular}{|llll|}
\hline $\begin{array}{l}\text { 0227776E } \\
\text { 8894396N }\end{array}$ & $\begin{array}{l}\text { Fazenda Boa Nova } \\
\text { (córrego Olimpo) }\end{array}$ & Novo Acordo & Lítico \\
\hline $\begin{array}{l}\text { 0227562E } \\
\text { 8894443N }\end{array}$ & $\begin{array}{l}\text { Margem do córrego } \\
\text { Olimpo }\end{array}$ & Novo Acordo & Lítico \\
\hline 0206950E & Morro do Homem & Novo Acordo & Arte rupestre \\
$8877429 \mathrm{~N}$ & & & Petroglifos \\
\hline 0258503E & Barra do córrego & Lizarda & Lítico \\
$8891605 \mathrm{~N}$ & Espingarda com o rio Sono & & \\
\hline $\begin{array}{l}\text { 0197511E } \\
\text { 8909384N }\end{array}$ & $\begin{array}{l}\text { Caverna em Novo } \\
\text { Horizonte }\end{array}$ & Rio Sono & $\begin{array}{l}\text { Arte rupestre } \\
\text { pinturas }\end{array}$ \\
& (rio Sono) & & \\
\hline
\end{tabular}

\section{Considerações finais}

As pesquisas arqueológicas realizadas no Jalapão revelaram um grande potencial arqueológico da região para a ocorrência de sítios associados a antigas populações indígenas. Entretanto, diante da carência de pesquisas nessas regiões dos cerrados do Brasil Central é imperativa a condução de mais projetos científicos, os quais somados às pesquisas já existentes poderão subsidiar a constituição de um panorama geral da arqueologia tocantinense.

A ocorrência de sítios em muito similares aos descritos para a 'tradição Itaparica' abre uma perspectiva para a possibilidade da presença humana no Jalapão atingir, ao menos, os 10.000 anos de antiguidade. Mesmo sabendo que a constatação de tal fato só é possível por meio de estudo sistemático, envolvendo prospecções intrusivas e datações radiocarbônicas, as semelhanças culturais aumentam as expectativas para a antiguidade do povoamento da região.

As ocupações cerâmicas no Jalapão apresentam semelhanças significativas com as descritas para a 'tradição Aratu-Sapucaí'. Entretanto, a mecanização destas áreas acarretou a fragmentação do material arqueológico. Assim sendo, a confirmação da tradição cerâmica também dependerá de futuros estudos.

Os alinhamentos de pedras são sítios extremamente particulares, atestando a diversidade da arqueologia tocantinense. A pouca ocorrência desta modalidade de sítio arqueológico no Brasil faz com que não muitos estudiosos

\section{Maracanan}


se dediquem a este campo. Algumas das estruturas do Jalapão, como o sítio megalítico de São Félix, são ideais para um estudo arqueoastronômico. Um estudo assim é necessário para compreender o universo imaterial destes povos, para os quais o ciclo solar ocupava posição fundamental. Ainda não é possível dizer se os enfileiramentos de pedras de Lizarda possuem alguma relação com os alinhamentos de pedras de Rio Sono e São Félix. Como não foi notada a existência de outras evidências arqueológicas nestes sítios, é impossível estabelecer qualquer tipo de relação entre estas estruturas e outros registros arqueológicos conhecidos para o Tocantins.

Os dados arqueológicos provenientes da região do Jalapão ainda são muito fragmentados e uma melhor caracterização das sociedades indígenas pré-coloniais que ali viveram dependerá de futuras pesquisas, indispensáveis para a formação de um plano de gerenciamento deste formidável patrimônio arqueológico. Todavia, as evidências ora levantadas atestam o enorme potencial da arqueologia nestas savanas tocantinenses. A variedade das modalidades de sítios arqueológicos e a ocorrência de fenômenos tão particulares, como o enfileiramento de seixos de Lizarda e o sítio megalítico de São Félix, são indicadores do desafio que a arqueologia enfrentará para o estudo e salvaguarda do patrimônio arqueológico do Jalapão nestas primeiras décadas do século XXI.

\section{Agradecimentos}

Os autores registram seus agradecimentos à Scientia Consultoria Científica, ao guia Ceir Rocha e à equipe do Laboratório de Geoprocessamento (LABGEO), da Faculdade de Ciências Humanas da UFGD, pela elaboração das pranchas, especialmente aos geógrafos Adelsom Soares Filho e Ângelo Nascimento. Os agradecimentos são estendidos ainda a Sibeli Aparecida Viana e Júlio Cezar Rubin de Rubin, da PUC Goiás, que leram os originais desse trabalho e apresentam relevantes sugestões para sua melhoria.

Janeiro | Dezembro 2011 
Notas e Referências

1 L.S. de AGUiAR, J. EREMITES DE OLIVEIRA. Alinhamentos de pedras atestam a existência de um culto solar pré-histórico em Jalapão/TO. Revista Geo, São Paulo, 2009, n. 3, pp. 1-4. Disponível apenas em http://revistageo.uol.com.br/cultura-expedicoes/0/artigo142382-1.asp [publicado em 23/06/2009]

2 P.I. SCHMITZ, A.S. BARBOSA. Horticultores pré-históricos do Estado de Goiás. São Leopoldo: Instituto Anchietano de Pesquisas, 1985.

3 A.S. BARBOSA et al. "Projeto Médio-Tocantins: Monte do Carmo, Fase Cerâmica Pindorama". Pesquisas, Série Antropologia. São Leopoldo, n. 34, 1982, p. 48-92.

4 O. DIAS JR. et al. "O Estado do Tocantins: relações arqueológicas”. In: O. DIAS et al. Estudos de Arqueologia Contemporânea. Palmas: Unitins/IAB, 2006.

5 O. DIAS JR. et al, Op. cit.

6 P.I. SCHMITZ. "A evolução da cultura no Sudoeste de Goiás”. Pesquisas, Série Antropologia. São Leopoldo, n. 31, 1980.

7 P.I. SCHMiTZ. "Caçadores-coletores do Brasil Central”. In. M.C. TENÓRIO. Pré-história da Terra Brasilis. Rio de Janeiro: Editora UFRJ, 1999, pp. 75-88.

8 P.I. SCHMITZ et al. Caiapônia: arqueologia nos cerrados do Brasil Central. São Leopoldo: Instituto Anchietano de Pesquisas, 1986.

9 P.I. SCHMITZ et al. Arte Rupestre no Brasil Central: pinturas e gravuras da pré-história de Goiás e oeste da Bahia. São Leopoldo: Instituto Anchietano de Pesquisas, 1984; P.I. SCHMITZ et al. "Arqueologia nos cerrados do Brasil Central: Serranópolis I". Pesquisas, Série Antropologia. São Leopoldo, n. 44, 1989; SCHMITZ, P. I. et al. "Arqueologia nos cerrados do Brasil Central: Serranópolis III”. Pesquisas, Série Antropologia. São Leopoldo, n. 60, 2004.

10 No âmbito da arqueologia brasileira, sobretudo a partir da década de 1960, o termo 'tradição' tem sido comumente utilizado para se referir a padrões tecnológicos que ocorrem em certos períodos e áreas geográficas, terminologia esta que pode servir para identificar 'horizontes arqueológicos'. Muitas vezes, tradições tecnológicas líticas e ceramistas foram definidas a partir de "fósseis guias", isto é, artefatos indicadores de certos padrões na produção de artefatos diversos. Hoje em dia, porém, muitas tradições têm sido revistas, como

\section{Maracanan}


é o caso da própria representação sobre a tradição Itaparica, conforme se pode constatar nos relevantes estudos de Emílio Fogaça ("A Tradição Itaparica e as indústrias líticas da Lapa do Boquete". Revista do Museu de Arqueologia e Etnologia, São Paulo, v. 5, pp. 145-158, 1995; "Nas entrelinhas da Tradição: os instrumentos de ocasião da Lapa do Boquete". Revista de Arqueologia, São Paulo, v. 10, pp. 71-88, 1997; Mãos para o pensamento. A variabilidade tecnológica de indústrias líticas de caçadores-coletores holocênicos a partir de um estudo de caso: as camadas VIII e VII da Lapa do Boquete (Minas Gerais, Brasil) - 12.000 / 10.500 B.P. Tese de Doutorado em História. Porto Alegre, PUCRS, 2001) (ver também M.M. do NASCIMENTO. Pedra que te quero palavra: discursividade e semiose no (con)texto arqueológico da tradição Itaparica. Tese de Doutorado em História. Porto Alegre: PUCRS, 2010). Embora não seja ignorada esta realidade, neste artigo não faremos uma discussão detalhada sobre o tema, embora fique a advertência de que esses termos são aqui empregados sem muito rigor e com a devida relativização.

11 A. PROUS. Arqueologia Brasileira. Brasília: UnB, 1992.

$12 \mathrm{~J}$. EREMITES DE OLIVEIRA, S.A. VIANA. "O Centro-Oeste antes de Cabral”. Revista USP, São Paulo, 2000, n. 44, v. 1, pp. 142-189.

13 P.I. SCHMITZ. Op. cit., 1986, p. 32.

14 P.I. SCHMITZ. Op. cit., 1999.

15 A. PROUS. Op. cit.

16 A.S. BARBOSA et al. Op. cit.

17 Idem, p.72.

18 P. I. SCHMITZ; A.S. BARBOSA. Op.cit.

19 O. DIAS JR. et al. Op. cit.

20 W. F. MORALES. "Um estudo de arqueologia regional no médio curso do rio Tocantins, TO, Planalto Central Brasileiro". Revista do Museu de Arqueologia e Etnologia. São Paulo: USP, 2007, v. 17, pp. 69-97.

21 J. EREMITES DE OLIVEIRA; S.A. VIANA. Op. cit.

22 I. WÜST. Continuidade e mudança: para uma interpretação dos grupos ceramistas pré-coloniais da bacia do rio Vermelho, Mato Grosso. Tese de Doutorado em Antropologia Social. São Paulo: USP, 1990.

23 E.R. OLIVEIRA. Aspectos da interação cultural entre os grupos ceramistas pré-coloniais do médio curso do rio Tocantins. Dissertação de Mestrado. Programa de Pós-Graduação em Arqueologia. São Paulo: USP, 2005.

Janeiro | Dezembro 2011 
24 I. WÜST. Op.cit

25 P. I. SCHMITZ, A.S. BARBOSA. Op.cit.

26 Idem.

27 O. A. GIRALDIN. A (tras)formação histórica do Tocantins. Goiânia: UFG, 2004.

28 O. DIAS JR. et al. Op. cit: pág. 209

29 C.A. SILVA. Confrontando mundos: os Xerente, Xavante, Xakriabá e Akroá e os contatos com os conquistadores da Capitania de Goiás (1749-1851). Dissertação de Mestrado em História. Dourados, UFGD, 2006.

30 P.I. SCHMITZ. Op. cit., 1989.

31 C.A. SILVA, Op. cit.

32 Idem.

33 Ibidem.

34 S.B. CALDARELLI. "Levantamento arqueológico em planejamento ambiental". Revista do Museu de Arqueologia e Etnologia (Série Suplemento). São Paulo, 1999, n. 3, pp. 347-369.

35 R.L.S. AGUIAR de; J. EREMITES DE OLIVEIRA. "Jalapão: pistas do passado em um patrimônio natural". Ciência Hoje. Rio de Janeiro, 2010, v. 45, n. 268 , pp. 28-33.

36 A.S. BARBOSA et al. Op. cit.

37 A. PROUS. Op. cit.

38 P.I. SCHMITZ et al. Op. cit., 1984.

Maracanan 